\title{
EWSR1/FEV Fusion Gene
}

National Cancer Institute

\section{Source}

National Cancer Institute. EWSR1/FEV Fusion Gene. NCI Thesaurus. Code C99226.

A fusion gene that results from a chromosomal translocation $\mathrm{t}(2 ; 22)(\mathrm{q} 36 ; \mathrm{q} 12)$ which fuses either the first seven or ten exons of the EWSR1 gene with exon 1 or 2 of the FEV gene. This rearrang ement is associated with Ewing tumor/peripheral primitive neuroectodermal tumor. 